\title{
PRÁTICAS DE PSICOLOGIA EXPERIMENTAL E PEDAGOGIA CIENTÍFICA NA ESCOLA NORMAL SECUNDÁRIA DE SÃO CARLOS: A CONCEPÇÃO DO EDUCADOR PAULISTA JOÃO TOLEDO
}

\author{
Maria de Lourdes Pinheiro ${ }^{1}$ \\ CIVILIS/FE/Unicamp
}

RESUMO

Numa perspectiva histórico-cultural e abrangendo o período de 1913 a 1921, este artigo apresenta uma discussão sobre a implantação da cadeira de Psicologia Experimental, Pedagogia e Educação Cívica e do Gabinete de Antropologia Pedagógica e Psicologia Experimental na Escola Normal Secundária de São Carlos, que servia aos professores da referida cadeira para a realização de exames psico-antropométricos. Exames de alunos parecem ter sido feitos regularmente de 1913 até aproximadamente 1920, mas, como se limitavam aos aspectos antropométricos, João Toledo, então lente da Escola Normal Secundária de São Carlos, manifestou sua crítica em periódicos educacionais que circulavam naquele momento.

Palavras-chave: João Toledo; Escola Normal; Psicologia Experimental; Pedagogia Científica.

\section{PRACTICE OF EXPERIMENTAL PSYCHOLOGY AND PEDAGOGY SCIENCE IN SECONDARY NORMAL SCHOOL OF SÃO CARLOS: THE CONCEPTION OF THE EDUCATOR OF SÃO PAULO JOÃO TOLEDO}

\begin{abstract}
In a historical-cultural perspective and covering the period 1913 to 1921 , this article presents a discussion on the implementation of the chair of Experimental Psychology, Pedagogy and Civic Education and the Office of Educational Anthropology and Experimental Psychology in Secondary Normal School of São Carlos, which served the teachers of that chair to carry out psycho-anthropometric examinations. Examination of students seem to have been made regularly from 1913 until about 1920, but as has been limited to anthropometric, João Toledo, then lens Secondary Normal School of São Carlos, expressed his criticism in educational journals that circulated at that time.
\end{abstract}

Keywords: João Toledo. Normal School. Experimental Psychology. Scientific Pedagogy

\section{Introdução}

O presente trabalho é parte integrante de tese de doutorado defendida em fevereiro de 2009, na Faculdade de Educação/Unicamp. O desenvolvimento da tese teve apoio financeiro da CAPES e esteve articulado a um projeto mais amplo financiado pela FAPESP, coordenado pela Profa. Dra. Maria Cristina Menezes (CIVILIS/FE/Unicamp). Abrangendo o período de 1913 a 1921, trata-se de uma discussão a respeito da implantação da cadeira de Psicologia Experimental, Pedagogia e Educação Cívica e do Gabinete de Antropologia Pedagógica e Psicologia Experimental na Escola Normal Secundária de São Carlos, numa perspectiva histórico-cultural, que "tem por principal objeto identificar o modo como em diferentes lugares e momentos uma determinada realidade social é construída, pensada, dada a ler" (CHARTIER, 1990, p. 16-17). 
Para Chartier (1999), a abordagem cultural da história resulta de um esforço para "entrar na complexidade de uma sociedade a partir de um elemento particular - uma biografia, uma existência singular, um evento, uma prática particular" (p. 11), pois, "a partir deste destino individual, desta prática específica, ou deste evento, se pode reconstruir a totalidade dos laços, interdependências, relações que definem o mundo social" (p. 11).

Hilsdorf (1986), por sua vez, ressalta que, ao se realizar um trabalho de investigação histórica sobre um determinado personagem, a revelação do perfil do pesquisado esclarece e amplia a compreensão do contexto em que ele viveu. Ao se estudar seu pensamento e obra, algumas questões estarão implícitas, como sua trajetória intelectual e posições assumidas, o que significa dizer que a obra de um autor acaba por refletir os movimentos e tendências de um dado momento, levando a uma melhor compreensão da época social e cultural em que viveu.

Nesse sentido, quando, em 1911, houve a reorganização do ensino normal paulista, as escolas complementares foram transformadas em escolas normais primárias e as escolas normais passaram a ser denominadas normais secundárias. Com a alteração, o curso normal secundário teve seus estudos pedagógicos ampliados e distribuídos em disciplinas de formação profissional: $11^{\mathrm{a}}$ e $12^{\mathrm{a}}$ cadeiras, ambas de Psicologia Experimental, Pedagogia e Educação Cívica, e 13 a cadeira, Métodos e Processos de Ensino, Crítica Pedagógica e Exercícios de Ensino. Além das disciplinas citadas, as escolas normais secundárias ganharam também, cada uma, um Gabinete de Antropologia Pedagógica e Psicologia Experimental para servirem aos professores das $11^{\mathrm{a}}$ e $12^{\mathrm{a}}$ cadeiras e para a realização de exames psicoantropométricos.

Os gabinetes inauguraram a prática científica paulista no campo da Psicologia da Educação, pois, antes desse período, a pequena produção psicológica que havia era de cunho especulativo, influenciada por diversas correntes filosóficas, sobretudo do século XIX, ou manifestavam opiniões pessoais de seus próprios autores, sem especialização nos temas que se referiam ao ensino ou à aprendizagem (TAVARES, 1996a). Porém, Tavares (1996a) considera que o grande mérito dos gabinetes (ou laboratórios, como às vezes eram chamados) foi o de realizarem os primeiros estudos experimentais sobre os diversos aspectos psicológicos (memória, atenção, discriminação visual, tátil, entre outros temas) difundindo para o público leigo, inclusive professores, as novas possibilidades de compreensão do indivíduo abertas pela Psicologia Científica.

\section{Psicologia Experimental e Pedagogia Científica}

Na Escola Normal Secundária de São $\operatorname{Carlos}^{2}$ (1), as aulas de Psicologia Experimental aconteciam no primeiro e no segundo ano (três aulas por semana cada seção), e as aulas de Pedagogia e Educação Cívica aconteciam no terceiro e no quarto ano (também três aulas por semana cada seção). A disciplina de Psicologia, porém, nem sempre teve uma concepção "científica e experimental".

Muitas vezes, principalmente no período 1890 a 1910, enquanto as pesquisas da psicometria e da psicofísica ainda gozavam de grande consideração no meio intelectual europeu, mas que cujos resultados ainda eram pouco conhecidos no Brasil, a perspectiva psicológica participava apenas como um "ponto de partida" para se analisar as questões educacionais (TAVARES, 1994, p. 04).

Desse modo, Tavares (1996b) observa que a psicologia, em São Paulo, teve que esperar até 1911 para conquistar uma considerável independência científica e teórica 
dentro do currículo do curso normal. Tal fato era consequência e causa da crença que considerava a psicologia a ciência mais importante, nesse momento, para a formação do professor primário (TAVARES, 1996b): consequência, na medida em que a inclusão dessa disciplina foi o reflexo da visão "psicologizante" de algumas autoridades escolares do período; e causa, já que o conhecimento psicológico assimilado, a partir de então, por um número cada vez maior de professores, ficou irrevogavelmente entendido como inerente às questões e à prática pedagógicas.

Em função disso, a partir de meados da década de 1910, houve uma firme convicção de que o desenvolvimento da disciplina de Psicologia Experimental provocaria um forte impulso no campo da teoria e da prática educacionais, ao mesmo tempo em que proporcionaria uma base científica na abordagem e solução dos problemas da educação (TAVARES, 1994). Os investimentos públicos no ensino paulista e a predominância do pensamento positivista foram, também, condições extremamente propícias para a difusão das teorias da "nova" psicologia no período. Nesse sentido, Tavares (1996a) destaca que o saber psicológico, que se apresentou nos discursos e práticas dos professores paulistas das primeiras décadas republicanas, associou-se fundamentalmente a dois dos maiores interesses da escola pública da época: a renovação e racionalização de seus métodos de ensino, e a regeneração da sociedade por meio da educação do indivíduo.

Em relação à Pedagogia, esta vinha sendo questionada desde meados do século XIX (na Europa e Estados Unidos), por seu repertório "antigo" de teorias e práticas, criticado por sua base alicerçada em princípios filosóficos nunca comprovados e acusado de ser fundado no senso comum (TAVARES, 1996a). Em substituição à "pedagogia ultrapassada", pesquisadores buscaram novas perspectivas para analisar e estabelecer o trabalho de ensinar e aprender, encarado agora por meio de uma visão cientificista importada das ciências positivas (como a Biologia, a Física e a Química). Nesse contexto, surgiu uma nova versão da Pedagogia, chamada de "científica".

Nesse sentido, quando Oscar Thompson ocupou o cargo de diretor da Escola Normal Secundária de São Paulo nomeou Clemente Quaglio para instalar um Gabinete de Antropologia Pedagógica e Psicologia Experimental na escola sob sua direção, com o objetivo de realizar medidas e avaliações antropológicas, fisiológicas e psicológicas de crianças.

Para Tavares (1996b), o qualificativo "pedagógica" ao designativo "antropologia", que formam o primeiro nome dado aos gabinetes criados nas escolas normais secundárias, deve ser entendido no sentido de delimitar que a antropologia praticada nesses locais deveria estar voltada às questões pedagógicas e escolares, não tendo, portanto, o mesmo sentido que tem hoje. Dessa forma, a análise antropológica nesse período detinha-se na análise biológica do comportamento humano e dedicava-se à medição craniométrica, considerada essencial para a análise das raças: era a "ciência das medidas do homem" e a psicometria era o seu complemento necessário, pois fornecia as medidas psicológicas próprias aos indivíduos de "uma certa raça" (memória, inteligência, atenção etc.).

Assim, o gabinete da Escola Normal Secundária de São Paulo, criado em 1912, foi anexado às cadeiras de Psicologia Experimental, Pedagogia e Educação Cívica. Carvalho (1997) considera que a justificativa para a instalação do gabinete, por parte de Thompson, era a necessidade de fazer a escola acompanhar a marcha científica que estava ocorrendo em toda parte a favor do ensino.

A escolha de Quaglio, um positivista por temperamento e convicção, para chefiar o gabinete provavelmente se deve ao fato de que ele havia implantado, em maio de 1909, um gabinete semelhante nas dependências de uma escola localizada em Amparo, tendo realizado experiências psicométricas com os alunos e pesquisado aspectos como fadiga 
muscular, sensibilidade auditiva e visual, tempo de reação e memória de aprendizagem. Os resultados dos estudos que desenvolveu sobre a infância foram publicados, posteriormente, num artigo da Revista de Ensino, em 1909.

Como chefe do gabinete da Escola Normal Secundária de São Paulo, Quaglio teria sido o primeiro a aplicar a escala métrica de inteligência de Alfred Binet e Théodore Simon em crianças das escolas da capital (POLIANTÉIA, 1946; MONARCHA, 1999). Em vista disso, Monarcha (1999) considera que "a pedagogia esboçada por Quaglio prefigura a "pedagogia científica" proposta pelo médico italiano Ugo Pizzoli no ano de 1914, durante sua estadia em São Paulo" (p. 256). Catani (2003), por sua vez, observa que o professor italiano parece ter sido uma influência muito forte, pois "de sua presença resultaram novas iniciativas no domínio das aplicações da psicologia à educação" (p. 196), como o convite feito a ele para que reorganizasse o gabinete da escola normal, até então chefiado por Quaglio.

Ugo Pizzoli já havia publicado uma coletânea de artigos com trabalhos experimentais sobre temas como raciocínio infantil, grafismo, memória, cinética, tipos intelectuais e associações de idéias. Por convite de Thompson, em 1914, Pizzoli veio a São Paulo contratado por um período de seis meses para ampliar o Gabinete de Antropologia Pedagógica e Psicologia Experimental da Escola Normal Secundária de São Paulo. Sua vinda foi descrita por Carlos da Silveira como uma tentativa do governo no sentido de "orientar a ação dos professores paulistas para uma pedagogia melhor, mais eficiente pelas suas bases psíquicas experimentais" (SILVEIRA, 1918, p. 85).

O professor italiano equipou o gabinete com aparelhos destinados à realização de investigações na área de senso-percepção e psicometria de modo geral e os estudos que realizou estavam centrados na observação positiva e na determinação das medidas das ligações entre o mundo físico e psíquico, utilizando procedimentos e técnicas da antropologia física e dos testes mentais. Monarcha (1999) observa que os dados levantados com esses procedimentos levavam à identificação das características físicas, intelectuais, morais e a consequente classificação do tipo de aluno, de forma que o gabinete acabou por gerar um movimento expressivo em torno da Pedagogia Científica, que vinha como solução para as demandas práticas que se fazia da ciência.

Além da reorganização do gabinete, Ugo Pizzoli ofereceu um curso de Pedagogia Científica, de 15 de junho a 15 de julho de 1914, destinado especialmente para os professores de Pedagogia, inspetores escolares e diretores de grupos escolares. Posteriormente, foi publicado o livro "O Laboratório de Pedagogia Experimental"; o livro, organizado, orientado e apresentado pelo próprio professor italiano, trazia as teses estudadas pelos professores que seguiram o curso, além de artigos de Oscar Thompson, Ruy de Paula Souza, Carlos Alberto Gomes Cardim, Roldão Lopes de Barros, Clemente Quaglio, Saverio Cristofaro e Joaquim A. de Sant'Anna.

Por fim, o livro trazia um modelo de "carteira biográfica escolar", idealizado por Pizzoli, que vinha a ser um caderno padronizado para a realização de inventário minucioso dos alunos dos grupos escolares, sendo composto por registros de interrogatórios e exames que resultariam em dados sócio-antropo-psicológicos das crianças.

Trazia, ainda, um relatório do curso, no qual o professor italiano expunha o programa do curso oferecido, composto por quarenta e seis lições teórico-práticas, e apresentava a relação dos professores, inspetores e diretores escolares, que haviam frequentado o curso num total de cinquenta e quatro nomes, entre eles Carlos da Silveira e João Toledo, lentes das $11^{\mathrm{a}}$ e $12^{\mathrm{a}}$ cadeiras de Psicologia Experimental, Pedagogia e Educação Cívica (respectivamente) da Escola Normal Secundária de São Carlos. 
Quando Pizzoli retornou à Europa, em novembro de 1914, o gabinete voltou à responsabilidade de Clemente Quaglio e, posteriormente, do professor de Psicologia Experimental, Pedagogia e Educação Cívica da Escola Normal Secundária de São Paulo, Sampaio Dória, porém, "sem despertar maior interesse” (TAVARES, 1996a, p. 04).

\section{O Gabinete de Antropologia Pedagógica e Psicologia Experimental de São Carlos}

Após a conclusão do curso oferecido por Ugo Pizzoli, João Toledo e Carlos da Silveira retornaram à escola normal em São Carlos. O Gabinete de Antropologia Pedagógica e Psicologia Experimental da escola, porém, só ficou completo após a transferência da instituição para um novo edifício, inaugurado em 18 de novembro de 1916, tendo ficado sob a responsabilidade de Manuel de Toledo Silva. Morila (2005) e Pirolla (1988) informam que os laboratórios da escola foram equipados com aparelhos de procedência européia, inclusive o gabinete, que "servia para treinamento dos professores em medições antropométricas, acuidade sensorial, auditiva, gustativa e tátil" (PIROLLA, 1988, p. 26).

No gabinete, os exames de alunos na escola normal em São Carlos parecem ter sido feitos regularmente de 1913 até aproximadamente 1920 (TAVARES, 1996b), porém limitando-se aos aspectos antropométricos, fato justificado pelo diretor Juvenal Penteado no relatório de 1914 (publicado na Revista de Ensino, jun./1915), sobre a falta de aparelhos necessários para outros estudos.

Infelizmente o gabinete de psicologia da Escola não dispõe ainda senão dos aparelhos adquiridos na época de sua instalação. São aparelhos suficientes para um curso regular, porém muito imperfeitos. A segunda encomenda feita na Europa foi interceptada pela guerra, e é provável que, tão cedo, não nos possa chegar às mãos.

Além do serviço prestado ao curso normal, o gabinete tem fornecido, todos os anos, os dados para a ficha antropométrica dos alunos da escolamodelo anexa, a qual foi instituída por esta diretoria em 1913, (...) como uma tentativa de sistematização desse serviço no nosso meio escolar (PENTEADO, 1915, p. 02).

Carlos da Silveira, então lente da $11^{\mathrm{a}}$ cadeira de Psicologia Experimental, Pedagogia e Educação Cívica, criticava o fato de se realizarem somente exames antropométricos, "puramente somáticos", e apresentou o artigo intitulado "Da educação dos professores", que foi publicado na Revista de Ensino (jun./dez. 1918). Silveira expunha que entendia por gabinetes de antropometria escolar as repartições anexas às escolas, encarregadas de uma investigação minuciosa e profunda da parte física da "nossa gente", para os fins que a ciência tinha em vista (antropológicos, fisiológicos, pedagógicos, sociais e político-administrativos).

Segundo o autor, seria de responsabilidade dos encarregados dos gabinetes promoverem investigações dessa natureza, a fim de determinarem as características do "tipo brasileiro normal", o que era uma indagação difícil, em virtude de analisar-se a "massa da população" e serem atendidas suas partes constitutivas (o "elemento nacional propriamente", o "elemento negro e mestiços dele", o "elemento indígena e suas combinações", e o "elemento estrangeiro de várias origens e suas misturas"). Argumentava, ainda, que "tomar medidas de conjunto, deixando de lado esses fatores, [era] empresa inútil por não permitir conclusões mesmo aproximadas, e perigosa por induzir em erro" (SILVEIRA, 1918, p. 85). 
Carlos da Silveira ressaltava, por fim, que quando os gabinetes foram criados não foram mesmo outros os intuitos da lei que os criou, "basta que se examinem as fichas adotadas entre nós para se verificar desde logo a superioridade dos dados puramente somáticos, sobre as indicações da natureza psicológica" (SILVEIRA, 1918, p. 85). Silveira considerava impróprio, então, o nome "gabinetes de psicologia experimental" e destacava que, quando o governo de São Paulo entendeu que convinha orientar a ação dos professores paulistas "para uma pedagogia melhor, mais eficiente pelas suas bases psíquicas experimentais", adotou as normas de tendência italiana, com a contratação do professor Ugo Pizzoli para dirigir o curso de Pedagogia Científica a mestres e diretores de escolas, "curso esse com chamada diária, programa, exames finais obrigatórios, notas e diplomas, oficial portanto" (SILVEIRA, 1918, p. 85).

Ora, os que acompanharam as lições do entusiasta cientista de Milão puderam ver que ele dava um desenvolvimento enorme ao estudo da parte física e da parte psicológica da criança, - pontos de vista estes que dominavam as aulas, - denominando psicologia apenas as questões referentes à educação dos órgãos dos sentidos, e a pouco mais do que isso (SILVEIRA, 1918, p. 85-86).

Apesar da crítica, a Revista da Escola Normal de S. Carlos publicou, em dezembro de 1917 e de 1918, uma tabela com a média das medidas antropométricas dos alunos, referentes à idade, sexo, média da estatura, média do peso, força muscular, medidas da cabeça, dentre outras medidas. Além disso, em 1916 havia sido estabelecido um programa de ensino para as cadeiras de Psicologia Experimental, Pedagogia e Educação Cívica das escolas normais secundárias.

\section{Psicologia Experimental e Pedagogia: concepções de João Toledo}

No relatório do ano letivo de 1914, o diretor da Escola Normal Secundária de São Carlos, Juvenal Penteado, destacava, entre outras questões, o ensino de Psicologia e Pedagogia:

O curso desta disciplina, iniciado em 1913, não passou, nesse ano, de um simples campo de experimentação e adaptação, devido não só à deficiência de livros e aparelhos como às dificuldades próprias a todas as matérias estranhas ao meio em que são introduzidas. Apesar disso, já nesse primeiro ano os resultados foram muito além do que se poderia esperar.

(...)

Adaptada convenientemente às exigências do curso normal e apresentada ao aluno sob o ponto de vista prático, puramente experimental, sobretudo em seu início, a psicologia é uma ciência francamente acessível, ainda mesmo aos alunos de mediano preparo. De posse dos conhecimentos, ainda que rudimentares, dos fenômenos psíquicos, o horizonte intelectual do aluno se alarga no domínio das especulações profissionais, e, ao entrar no campo da doutrina pedagógica, a matéria se lhe afigura um prolongamento, sem solução de continuidade, dos estudos anteriormente feitos (PENTEADO, 1915, p. 01-02).

Entretanto, para João Toledo, que apresentou uma exposição sobre o ensino da Psicologia e da Pedagogia no ensino normal, em julho de 1921, numa reunião composta 
por diversos profissionais do ensino paulista para tratar do estudo de questões de interesse geral do ensino, a convite do diretor geral da Instrução Pública, Guilherme Kuhlmann, o termo experimental não se aplicava à disciplina de Psicologia ${ }^{3}$ (2). Toledo argumentava que:

Para experiências em classe, - como a determinação de limiar de percepção, em "múltiplas sensibilidades"; determinação de tempo de reações diversas, etc. - faltar-nos-ia tudo, desde o aparelhamento indispensável e custoso até o tempo largo que os horários não comportam. E além disso, os fatos puramente psíquicos, suscetíveis de medida, ótimos para as induções de gabinete, aproveitariam pouco aos que se destinam à pratica de ensino. Desses, nosso programa deverá compreender somente aqueles, como a atenção e a memória, cuja medida, de fácil execução, é auxiliar poderoso para o conhecimento seguro do educando. Os outros, cuja medição comumente se executa, como a acuidade visual e a auditiva, e a força muscular, pertencem ao domínio da pedagogia. Incluídos, porém, em nosso programa, como deverão ser, ainda não justificam o qualificativo "experimental", - ampliam apenas o campo de estudo, que tomará aspecto novo e poderá, então, denominar-se - "psicopedagogia" (TOLEDO, 1921, p. 338).

Ainda sobre o ensino de Psicologia, Toledo sugeria:

"A preocupação de fazerem-se experiências em classe, fica desde logo
afastada". O termo "experimental", que acompanhou a psicologia,
lecionada nas Normais - secundárias, (...) significaria uma prevenção
contra o estudo de questões metafísicas, interessantes, é certo, mas quase
inúteis para efeitos escolares; significaria antes a orientação a dar-se à
escolha de lições, que versariam sobre fatos comprovados já, pela
observação e pela experimentação, fora de qualquer dúvida, explicados
em suas causas próximas, e constitutivos do patrimônio indestrutível da
ciência (TOLEDO, 1921, p. 336-337).

Já com relação ao ensino da Pedagogia, o primeiro cuidado seria definir, de modo preciso, sobretudo a partir do ponto de vista brasileiro, as finalidades da educação em geral, a ser orientada "em toda a parte do mundo, no sentido de alcançar a moralidade do educando" (TOLEDO, 1917, p. 26).

A compreensão da moralidade como a finalidade da educação em João Toledo foi por ele discutida no artigo A Escola Brasileira (publicado na Revista da Escola Normal de S. Carlos, dez./1917, e na Revista de Ensino, dez./1917 a mar./1918) e remete a Herbart, para quem a moralidade era o fim básico da educação, entendida como o processo de aperfeiçoamento do caráter humano. Por moralidade, Toledo entendia a obediência e o respeito à lei e aos bons costumes, devendo ainda ser indicado aos alunos os ideais nacionais que os levariam a realizar aspirações, despertando iniciativas.

Fora destes moldes, a cadeira de pedagogia será morta e, portanto, ineficiente. Seu objeto estará em si mesmo - saber para saber, se é que a verdade não seja esta - saber para fazer exames... Este parece-me, é o ponto de apoio em que os espíritos se estribarão para galgar o objetivo indicado pelos fins nacionais de nossas escolas (TOLEDO, 1921, p. 339). 
Depois de conhecidos os fins da educação e os ideais nacionais que auxiliariam o trabalho do professor na formação da moralidade do aluno, que expressa bem o sentimento nacionalista da época, João Toledo argumentava que o passo seguinte era conhecer o educando, na sua "feição biológica, e os agentes modificáveis pelo homem, que sobre seu físico exercem influência, acelerando ou retardando o crescimento" (1921, p. 339).

Mas Toledo observava, "com desprazer", que a Pedagogia ainda não havia legado ao magistério as convicções que mudariam a face da educação brasileira, fato que tornava as escolas "incolores, inexpressivas, amorfas", verdadeiras "colchas de retalhos", por serem organizadas como escolas francesas, americanas, argentinas, e não conforme as "conveniências e necessidades do país". Para ele, não havia má vontade, mas "falta de publicações pedagógicas que nos orientem sobre o que devem fazer nossas escolas" (TOLEDO, 1917, p. 33).

Além de artigos como os de Carlos da Silveira e de João Toledo, outras críticas começaram a ser feitas por alguns educadores com relação à disciplina de Psicologia Experimental, Pedagogia e Educação Cívica, sobretudo no que se refere à associação da Psicologia e Pedagogia com a Educação Cívica. Entre eles Sampaio Dória, para quem a educação moral e cívica não possuía relação de unidade com as outras duas disciplinas. Para Dória, o legislador, entendendo que a Educação Cívica era um capítulo da Pedagogia, havia tomado o termo "pedagogia" como sinônimo de educação; porém, somente a unidade entre Psicologia e Pedagogia era lógica, porque a primeira assentava as leis de que a segunda se valia. A justificativa para tal associação entre as três disciplinas provavelmente decorria, na consideração apresentada por Tavares (1996b), do fato de que estas últimas foram concebidas pelos legisladores como responsáveis por encontrar os melhores meios para moldar em cada criança os atributos morais tidos como ideais.

\section{Considerações Finais}

Para muitos educadores paulistas, a psicologia passou a ser considerada como a ciência mais importante para a formação do professor primário, especialmente a partir de 1910. Em função disso, firmou-se a convicção de que o desenvolvimento da disciplina de Psicologia Experimental provocaria um impulso no campo da teoria e da prática educacionais e proporcionaria a base científica para a abordagem e solução dos problemas da educação como, por exemplo, a renovação e racionalização dos métodos de ensino, e a regeneração da sociedade por meio da educação do indivíduo.

Por sua vez, a Pedagogia vinha sendo questionada desde meados do século XIX, em países europeus e nos Estados Unidos, por seu repertório de teorias e práticas considerado ultrapassado, o que levou pesquisadores a buscarem novas perspectivas para analisar e estabelecer o trabalho de ensinar e aprender, por meio de uma visão cientificista importada das ciências positivas, como a Biologia, a Física e a Química, fato que levou ao surgimento de uma nova versão da Pedagogia, chamada de científica.

Nesse sentido, com a reorganização do ensino normal paulista, em 1911, ampliouse os estudos pedagógicos das escolas normais secundárias, sobretudo com a criação de duas cadeiras de Psicologia Experimental, Pedagogia e Educação Cívica, além da instalação de gabinetes de Antropologia Pedagógica e Psicologia Experimental que, associados às cadeiras citadas, serviriam para a realização de exames psicoantropométricos.

Na Escola Normal Secundária de São Carlos, porém, Carlos da Silveira criticava o fato de que os exames de alunos na instituição limitavam-se aos aspectos antropométricos, razão pela qual considerava o nome gabinete de psicologia experimental inapropriado, 
devendo antes ser chamado de gabinete de antropometria escolar. João Toledo, por sua vez, considerava que o termo experimental não se aplicava à disciplina de Psicologia, uma vez que faltavam desde o aparelhamento indispensável e custoso até o tempo largo que os horários não [comportavam].

Além das observações dos lentes da escola normal de São Carlos, outras críticas começaram a ser feitas em relação à junção da Psicologia e da Pedagogia com a Educação Cívica, por entenderem que não havia relação de unidade entre elas; apenas a união entre Psicologia e Pedagogia era lógica, porque a primeira assentava as leis de que a segunda se valia.

No entanto, as características dos estudos desenvolvidos nos gabinetes por profissionais ligados ao ensino, sobretudo em relação à psicologia, é um importante indício da constituição dos saberes e das práticas pedagógicas que foram então estabelecidas.

\section{Referências}

CARVALHO, Marta Maria Chagas de. Quando a história da educação é a história da disciplina e da higienização das pessoas. In: FREITAS, Marcos Cezar de (org.). História social da infância no Brasil. São Paulo: Cortez Editora, 1997, p. 269-287.

CATANI, Denice Barbara. Educadores à meia-luz: um estudo sobre a Revista de Ensino da Associação Beneficente do Professorado Público de São Paulo. Bragança Paulista, SP: EDUSF, 2003.

CHARTIER, Roger. Por uma sociologia histórica das práticas culturais. In: CHARTIER, Roger. A história cultural: entre práticas e representações. Trad. Maria Manuela Galhardo. Rio de Janeiro: Bertrand Brasil; Lisboa: Difel, 1990, p. 13-28.

Entrevista com Roger Chartier. Pós-História, Assis, SP, vol.07, p. 11-30, 1999.

HILSDORF, Maria Lucia Spedo. Francisco Rangel Pestana: jornalista, político, educador. São Paulo: Tese de Doutorado, Faculdade de Educação da Universidade de São Paulo, 1986.

MONARCHA, Carlos. Escola Normal da Praça: o lado noturno das luzes. Campinas: Editora da UNICAMP, 1999. (Momento)

MORILA, Ailton Pereira. Um monumento na avenida: a Escola Normal de São Carlos. Revista HISTEDBR On-line, Campinas, SP, n.19, p. 40-62, set. 2005.

O LABORATORIO de Pedagogia Experimental. Escola Normal Secundaria de São Paulo. São Paulo: Typ. Siqueira, Nagel \& Comp., 1914.

PENTEADO, Juvenal. Do curso de Psicologia Experimental. Revista de Ensino, SP, ano XIV, n.1, p. 01-13, jun./1915.

PINHEIRO, M. L. Trajetória e interlocuções do educador paulista João Toledo (19001939): a permanência dos modelos de lição. Tese (Doutorado). Campinas, SP: Faculdade de Educação da Universidade de Estadual de Campinas, 2009.

PIROLLA, Maria Christina Girão. Memórias do Instituto (1911-1976). São Carlos, SP: Camargo Artes Gráficas, 1988.

POLIANTÉIA Comemorativa. Centenário do Ensino Normal de S. Paulo (1846-1946). São Paulo: Gráfica Bréscia, 1946. 
SILVEIRA, Carlos da. Da educação dos professores. Revista de Ensino, SP, ano XVIII, n.1-4, p. 7686, jun./dez. 1918.

TAVARES, Fausto Antonio Ramalho. A Psicologia e a formação do sistema público de ensino no Estado de S. Paulo. I Simpósio de Pesquisa da FEUSP, SP, vol. 31, 1994, 10p. (Estudos e Documentos)

Psicologia e saberes pedagógicos em S. Paulo: o caso dos laboratórios de Pedagogia Experimental (1912-1930). América Latina e Caribe e os Desafios da Nova Ordem Mundial. Livro de Ata. V Congresso da Sociedade Latino-americana de Estudos sobre América Latina e Caribe, SP, vol. II, 1996a, 07p.

A ordem e a medida: escola e psicologia em São Paulo (1890 a 1930). São Paulo: Dissertação de mestrado, FEUSP, 1996 b.

TOLEDO, João. A escola brasileira. Revista de Ensino, SP, ano XVI, vol. 10, n.3-4, p. 26-34, dez./1917 a mar./1918.

Introdução aos programas de psicologia, pedagogia e metodologia das escolas normais paulistas. Anuário do Ensino do Estado de São Paulo (1920-1921), SP, 1921, p. 336-343.

Notas

${ }^{1}$ Pesquisadora do CIVILIS (Grupo de Estudos e Pesquisas em História da Educação, Cultura Escolar e Cidadania) da Faculdade de Educação da Universidade Estadual de Campinas. Possui doutorado em Educação pela FE/Unicamp (área de História, Filosofia e Educação). Email: pinheiro.lou@ gmail.com

2 Atual EE "Álvaro Guião".

${ }^{3}$ Nessa ocasião, já havia sido implantada a reforma do ensino paulista de 1920, proposta por Sampaio Dória. A disciplina Psicologia Experimental, Pedagogia e Educação Cívica, do curso normal secundário (alterado para curso normal), teve o termo experimental suprimido e passou a ser denominada Psicologia e Pedagogia, sendo dissociada da Educação Cívica.

Recebido em agosto-13

Aprovado em novembro-13 